\title{
Research on the Key Driving Factors of Prefabricated Buildings Based on DEMATEL method
}

\author{
Xizhen $\mathrm{Gao}^{1}$, Jiantong Zheng* \\ ${ }^{1}$ School of management, Tianjin University of Technology, Tianjin 300384, China \\ *School of management, Tianjin University of Technology, Tianjin 300384, China
}

\begin{abstract}
This paper identifies 18 driving factors of prefabricated buildings through literature review. After that, this paper collected corresponding questionnaires from industrial experts to clarify the relationships among these driving factors, and establishes a hierarchical relationship diagram of driving factors based on DEMATEL method, reveals the key direct driving factors of prefabricated buildings. Finally, puts forward suggestions to promote prefabricated buildings in China.
\end{abstract}

\section{Introduction}

As the pillar industry of the national economy, the construction industry is still a traditional industry that is labor-intensive and relatively backward in production methods. The construction methods are extensive and the organization methods are fragmented. In particular, the construction products provided by this traditional construction method can no longer meet the beautiful needs of people for high-quality buildings and the quality of living environment, the extensive development model can no longer meet the requirements of the era of highquality development of the construction industry. Therefore, the development of prefabricated buildings is a major change in construction methods. It is an inevitable requirement for the new era to implement new development concepts and achieve high-quality development.

There are many related studies on prefabricated buildings in academia. Qi Baoku ${ }^{[1]}$ discussed the comprehensive benefits of prefabricated buildings, calculated their economic benefits based on the construction and use costs of prefabricated projects, and introduced the carbon emission and energy conservation theory to study environmental benefits. They also theoretically analyzed other benefits. ZHAO Liang $^{[2]}$ used the analytic hierarchy process to analyze the key influencing factors of assembly project costs from the four aspects of design, management, technology and policy. Part of the related research starts from the obstacles faced by prefabricated buildings and explores corresponding cracking strategies ${ }^{[3-4]}$. The above research and its countermeasures and suggestions have important reference value for China to accelerate the implementation of prefabricated buildings. However, there are still few research results on the driving factors. Therefore, this paper explores the key driving factors and their relationship of prefabricated buildings in China, and proposes corresponding enlightenment suggestions.

\section{Selection of driving factors for prefabricated buildings}

This article collects relevant literature on fabricated buildings in recent years, 19 drivers are summarized (Table 1). Obviously, these driving factors are relatively scattered, with many dimensions and levels, the inherent logic is unknown, and the interrelationship between the factors is fuzzy. In the actual assembly construction process, analyzing the key driving factors and the relationship between them, and formulating a reasonable solution are effective ways to enhance the successful construction of prefabricated buildings.

Table 1. Drivers of prefabricated buildings

\begin{tabular}{|c|c|c|c|}
\hline Factor number & Driving factors & Factor number & Driving factors \\
\hline F1 & Reduced field operations & F10 & $\begin{array}{c}\text { Precast part doubles as a } \\
\text { template }\end{array}$ \\
\hline F2 & $\begin{array}{c}\text { Shorten the construction } \\
\text { period }\end{array}$ & F11 & $\begin{array}{c}\text { reduce environmental } \\
\text { pollution, Green }\end{array}$ \\
\hline F3 & High quality building & F12 & Save human resources \\
\hline F4 & $\begin{array}{c}\text { Convenient on-site } \\
\text { management }\end{array}$ & F13 & $\begin{array}{c}\text { Improve workers' } \\
\text { working environment }\end{array}$ \\
\hline F5 & $\begin{array}{c}\text { Little impact on climatic } \\
\text { conditions }\end{array}$ & F14 & $\begin{array}{c}\text { Promote industry upgrade } \\
\text { and change }\end{array}$ \\
\hline
\end{tabular}

\footnotetext{
* Corresponding author: 15630211067@163.com
} 


\begin{tabular}{|c|c|c|c|}
\hline F6 & $\begin{array}{c}\text { Guaranteed component } \\
\text { quality }\end{array}$ & $\mathrm{F} 15$ & Good market prospects \\
\hline F7 & Beautiful appearance & $\mathrm{F} 16$ & High security \\
\hline F8 & $\begin{array}{c}\text { Save energy and reduce } \\
\text { consumption, improve } \\
\text { resource utilization }\end{array}$ & $\mathrm{F} 17$ & $\begin{array}{c}\text { Design and quality } \\
\text { standards and documents } \\
\text { are gradually improved }\end{array}$ \\
\hline F9 & Policy Support & $\mathrm{F} 18$ & $\begin{array}{c}\text { High construction } \\
\text { efficiency }\end{array}$ \\
\hline
\end{tabular}
ySis of key driving factors based
MATEL model

\section{Analysis of key driving factors based on DEMATEL model}

\subsection{Basic principles of the DEMATEL model method}

The DEMATEL method was proposed by scholars A. Gabus and E. Fontela of the Battelle Laboratory in the United States in 1971. It is a method proposed to screen complex main elements, identify the interaction between elements in the system, and simplify the process of system structure analysis ${ }^{[5]}$. The Grey method is a mature method for solving problems related to uncertain decisions. This method uses interval grey numbers, that is, the description of a problem does not have a more accurate definition. The description value of the problem may exist in an approximate interval. Using a numerical interval to describe a problem can overcome the lack of concreteness of expert evaluation, and ultimately make the decision result closer to reality. Therefore, this article combines Grey-DEMATEL to study, which can reduce the research error caused by the subjectivity of expert scores is too strong, and clarify the intricate relationship between the driving factors of prefabricated buildings.

\subsection{Specific steps of the DEMATEL method}

(1) Constructing a direct impact matrix

Firstly, the influencing factors were selected as the research objects, and the correlation between the factors was determined by the expert scoring method. Comprehensively consider the stakeholders in the prefabrication assembly process, compare the influence relationships between various factors, and use letter symbols to indicate the degree of mutual influence between the two constraints in the system. Finally, the grey number theory is combined to form a matrix form.

(2) Establishing each weight matrix

Because each investigator has different knowledge and emphasis on prefabricated buildings, the weight given to each expert will be different, so the grey number theory is also used to blur the weight of the evaluation experts.

(3) Calculate direct impact matrix and comprehensive impact matrix

First calculate the direct impact matrix. Using formula to clear the grey number matrix, we get the direct influence matrix $\mathrm{C}$ :

$\mathrm{C}_{\mathrm{ij}}=\mathrm{w}_{1} \mathrm{C}_{\mathrm{ij}}^{1}+\mathrm{w}_{2} \mathrm{C}_{\mathrm{ij}}^{2}+\mathrm{w}_{3} \mathrm{C}_{\mathrm{ij}}^{3} \cdots+\mathrm{w}_{\mathrm{n}} \mathrm{C}_{\mathrm{ij}}^{\mathrm{n}}, \sum_{\mathrm{i}=1}^{\mathrm{n}} \mathrm{W}_{\mathrm{i}}=1(1)$

The direct impact matrix $\mathrm{C}$ is standardized, and the normalization directly affects the matrix A.

$$
\mathrm{A}=\beta * \mathrm{C}
$$

(4) Analysis of centrality and cause of influencing factors

Calculate the influence degree $\mathrm{G}$, influence degree $\mathrm{T}$, center degree $\mathrm{X}$, and cause degree $\mathrm{Y}$ of each driving factor according to the comprehensive influence matrix D. The calculation formula is as follows:

$$
\begin{gathered}
G_{i}=\sum_{i=1}^{n} D_{i j}(i, j=1,2,3 \cdots n) \\
T_{i}=\sum_{i=1}^{n} D_{i j}(i, j=1,2,3 \cdots n) \\
X_{i}=G_{i}+T_{i}(i=1,2,3 \cdots n) \\
Y_{i}=G_{i}-T_{i}(i=1,2,3 \cdots n)
\end{gathered}
$$

\section{Identification of key driving factors based on DEMATEL method}

The analysis of the key driving factors was conducted in the form of interviews and questionnaires. The questionnaires were issued mainly to construction workers and construction managers. A total of 15 questionnaires were distributed, removing invalid questionnaires with regular or highly repeated questions, and 12 valid questionnaires were recovered, with a recovery rate of $80 \%$. Calculate the direct impact matrix according to the above DEMATEL method steps, and use MATLAB 2017b software to calculate the comprehensive impact matrix $\mathrm{D}$, centrality, and cause degree, as shown in Table 2 below, and draw a causality diagram based on the centrality and cause degree in Table 2, As shown in Figure 1.

Table 2. Comprehensive influence of driving factors

\begin{tabular}{|c|c|c|c|c|}
\hline $\begin{array}{c}\text { Influencing } \\
\text { factors }\end{array}$ & $\begin{array}{c}\text { Impa } \\
\text { ct G }\end{array}$ & $\begin{array}{c}\text { Affected } \\
\text { degree T }\end{array}$ & $\begin{array}{c}\text { Central } \\
\text { ity X }\end{array}$ & $\begin{array}{c}\text { Cause } \\
\text { Degree Y }\end{array}$ \\
\hline F1 & 3.911 & 3.144 & 7.055 & 0.767 \\
\hline F2 & 3.359 & 2.823 & 6.182 & 0.537 \\
\hline F3 & 3.64 & 2.712 & 6.352 & 0.928 \\
\hline F4 & 2.962 & 3.345 & 6.307 & -0.383 \\
\hline F5 & 2.354 & 2.835 & 5.189 & -0.481 \\
\hline F6 & 2.812 & 3.451 & 6.263 & -0.638 \\
\hline F7 & 3.232 & 2.985 & 6.217 & 0.248 \\
\hline F8 & 2.985 & 2.508 & 5.493 & 0.477 \\
\hline F9 & 1.958 & 3.514 & 5.472 & -1.557 \\
\hline F10 & 1.995 & 2.24 & 4.234 & -0.245 \\
\hline F11 & 3.149 & 3.585 & 6.734 & -0.435 \\
\hline F12 & 2.964 & 2.936 & 5.9 & 0.028 \\
\hline F13 & 3.262 & 3.302 & 6.564 & -0.04 \\
\hline F14 & 2.472 & 2.734 & 5.207 & -0.262 \\
\hline
\end{tabular}




\begin{tabular}{|c|c|c|c|c|}
\hline F15 & 1.992 & 2.875 & 4.867 & -0.883 \\
\hline F16 & 2.523 & 2.797 & 5.32 & -0.274 \\
\hline F17 & 3.377 & 3.279 & 6.655 & 0.098 \\
\hline F18 & 3.69 & 1.574 & 5.264 & 2.117 \\
\hline
\end{tabular}

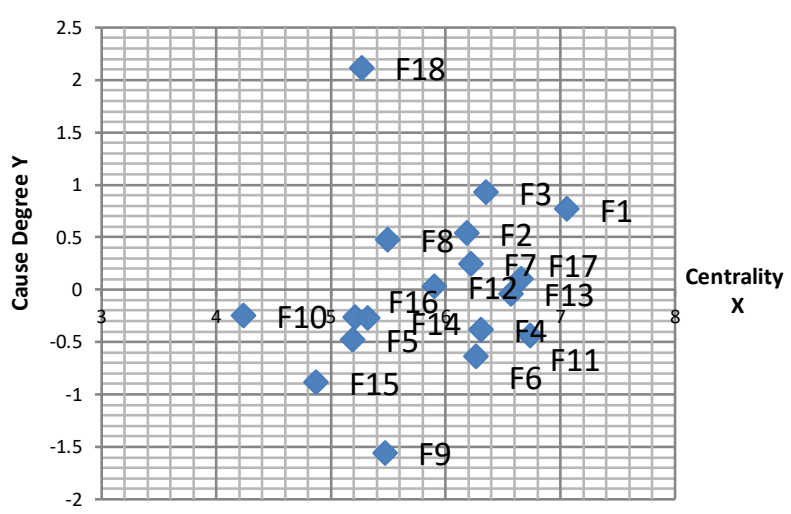

Fig. 1. Cause-Result Analysis Diagram

\section{Results analysis}

As can be seen from Table 2 and Figure 1, the cause value greater than 0 is the direct driving factor. Including "shorten the construction period", Design and quality standards and documents are gradually improved ", "higher building quality", "beautiful appearance", etc., these factors are the direct driving factors to promote the prefabricated building. For example, many construction projects now have strict schedule requirements, which are difficult to meet with traditional construction methods, while prefabricated technology can effectively shorten the construction period. If the construction period of a project is shorter than a reasonable construction period, it is suggested that the construction enterprises transform part of the on-site work into factory production, then they need to do a good job of the preliminary construction split and component design work, and do a good job of site management during the construction process.

Factors with a cause value less than 0 are indirect drivers and they can convey the relationship between the factors. "Policy support" is an aspect that cannot be ignored in the implementation of prefabricated buildings, because the cost of prefabricated buildings is often higher than traditional construction methods. Especially when the relevant units use the prefabricated building form for the first time or have not achieved the benefits of scale, preferential policies such as subsidies, incentives, tax reductions and exemptions are important driving factors for the comprehensive implementation of prefabricated buildings ${ }^{[6]}$. Therefore, the government should introduce and implement a system of preferential policies, and construction units, design units, construction units, component factory production units, and other assembly building-related enterprises and institutions should do a good job of coordination.
The greatest centrality value is the fundamental driving factor. This factor is "component factory production, reducing on-site operations." It is also the most essential feature of prefabricated buildings, and has profoundly affected many other factors. Due to the factory production of components, a series of on-site work is converted into factory production, which greatly reduces on-site operations, which results in high construction efficiency and more guaranteed component quality. From a worker and environmental perspective, this factor also has a significant impact on related factors. Therefore, the factor of "factory factory production and reduction of field operations" is very important, and it is the basis of many other driving factors. In order to achieve this goal, practitioners in prefabricated buildings need to consider both factory production and on-site construction. First of all, it is necessary to improve the factory production of components to ensure the production quality and supply capacity of assembled building components of the factory. In addition, prefabricated building construction site operations are reduced and construction methods are changed. On-site construction needs to innovate construction and management modes (such as EPC, full-process consulting) and improve related technical standard systems based on prefabricated concrete, steel, bamboo, and other structural forms. First-line operators are trained in key processes such as structural connection, sleeve grouting, and waterproof insulation to ensure the quality of field operations.

\section{Conclusion}

In China, prefabricated buildings have become a national strategy in recent years. At the same time as governments at all levels have vigorously promoted them, related academic research has also exploded. In order to explore the internal relationship of the driving factors, this paper uses literature analysis, expert interviews, DEMATEL method and MATLAB software. The key driving factors were found to be "shortening the construction period", "conducive to site management", "design and quality standards and documents are gradually improved", "higher building quality", "beautiful appearance" and "policy support", etc. "The factory production of components and the reduction of on-site operations" are the fundamental driving factors, clarifying the internal relationship of each driving factor. This paper analyzes the driving factors of prefabricated buildings and their relationships through a combination of qualitative and quantitative methods, and proposes countermeasures to accelerate the implementation of prefabricated buildings in China, which has significant theoretical and practical significance.

\section{References}

1. Qi Baoku, Zhu Ya, Ma Bo, Liu Shuai. Analytic Method Study of Comprehensive Benefit of Precast Building[J]. Construction Technology, 2016(4):3943. 
2. ZHAO Liang, HAN Quqiang, Research on the Influencing Factors of Prefabricated Building Cost [J]. Construction Economy, 2018(5); 25-29.

3. QIN Xuan, LI Aolei, ZHANG Rong, et al. Research on the relationship between the influencing factors of construction industrialization based on ISM: Survey from Xiamen[J]. Journal of Chongqing University (Social Science Edition), 2017(6): 30-40.

4. Mao C, Shen Q, Pan W, et al. Major barriers to offsite construction: The developer's perspective in
China[J]. Journal of Management in Engineering, 2013, 31(3): 1-8

5. Dang Yang Yang Yinsheng. Analysis on the Influencing Factors of the Development of Agricultural Think Tanks Based on the DEMATEL Method [J]. Journal of Modern Information, 2019, 39(11): 113-120+136.

6. Chen Wei, Wu Ya-shuai, et al. Construction Cost Factor Analysis of Prefabricated Building Based on Structural Equation Model [J]. Journal of Civil Engineering and Management, 2019(5): 50-5 